\title{
RELATIONSHIPS AMONG REPEATED SPRINT TESTS AND AEROBIC FITNESS IN ADOLESCENT TENNIS PLAYERS
}

\author{
Igal Tsiprun ${ }^{1}$, Tamir Eisenstein ${ }^{1}$, Alon Eliakim $^{1,2}$, Dan Nemet ${ }^{2}$, \\ YOAV MECKEL ${ }^{1}$ \\ ${ }^{1}$ Zinman College of Physical Education and Sport Sciences, Wingate Institute, \\ Netanya, Israel \\ ${ }^{2}$ Child Health and Sport Center, Pediatric Department, Meir Medical Center, \\ Sackler School of Medicine, Tel-Aviv University, Israel
}

\begin{abstract}
The aim of this study was to determine the performance indices (ideal sprint time - IS, total sprint time - TS, and performance decrement - PD) of two repeated sprint test (RST) and to examine their relationships with the aerobic fitness of young tennis players. Fifteen young (age 14.7 $\pm 1.0 \mathrm{yrs}$ ) tennis players performed three tests: an aerobic power test ( $20 \mathrm{~m}$ shuttle run), and two different RST protocols $(12 \times 20 \mathrm{~m}$ and $12 \times 10 \mathrm{~m}$ runs $)$. Peak heart rate was significantly higher in the $20 \mathrm{~m}$ protocol compared to the $10 \mathrm{~m}$ protocol while no significant difference was found in the PD of the two RST protocols. Significant positive correlations were found between the ISs and the TSs ( $r=0.946$ and $r=0.932$, respectively), but not between the PDs of the two RST protocols. Significant negative correlations were found between TS and IS and aerobic fitness during the $10 \mathrm{~m}$ protocol ( $\mathrm{r}=-0.594$ and $\mathrm{r}=-0.595$, respectively) and the $20 \mathrm{~m}$ protocol ( $\mathrm{r}=-0.757$ and $\mathrm{r}=-0.716$, respectively), but not between $\mathrm{PD}$ and the aerobic fitness in both RST protocols. Both short and long RST protocols represent similar anaerobic capabilities. In addition, the aerobic energy system serves as a significant factor in both RST protocols. However, it seems that the involvement of the aerobic system is more significant in the long than in the short repetition RST protocol.
\end{abstract}

Keywords: repeated sprint test, tennis, aerobic, fitness, anaerobic fitness 


\section{INTRODUCTION}

Tennis is an intermittent-type game characterized by repeated intense short activities with short periods of rest between efforts. The duration of work and rest periods during a tennis match is $1-10 \mathrm{~s}$ and $10-20 \mathrm{~s}$, respectively $[3,10]$. The total match time in tennis could last between 60 to $210 \mathrm{~min}$ with a single point length of 1-10 s. The precise match time and intensity is dependent upon the style of play (attacking or defensive), type of court surface (soft or hard), and motivational aspects $[6,12]$. In addition, environmental factors have been reported to influence the pattern of activity and recovery, and the physiological responses, during the game $[2,10]$. The average physiological responses to a tennis match have been reported to be rather modest, with mean exercise intensities less than $60-70 \%$ of maximal oxygen consumption $\left(\mathrm{VO}_{2} \mathrm{max}\right)$ and mean heart rates of $60-80 \%$ of maximum values. Blood lactate concentrations usually remain low $(1.8-2.8 \mathrm{mmol} / \mathrm{l})$ during tennis match $[9,10]$. However, occasionally, during long and intense rallies, lactate concentration may increase up to $7 \mathrm{mmol} / \mathrm{l}$, suggesting increased use of anaerobic glycolytic processes to supply energy [14].

The small dimensions of tennis court ( $11.9 \mathrm{~m}$ long and $8.2 \mathrm{~m}$ wide) limit the maximal sprint length. The short high-intensity type activities in the game rely mostly on anaerobic breakdown of creatine phosphate for energy production in the activated muscles. Consequently, tennis may be classified as a mainly anaerobic type of sport $[8,15]$. However, despite the start-and-stop nature, tennis has also an aerobic component because high-energy phosphates used for immediate muscle energy requirements are predominately resynthesized by oxidation during recovery periods $[7,19]$.

One reliable [4] and valid [1] method of evaluating the athlete's ability to repeatedly performed high intense efforts is the repeated sprint test (RST). This test usually involves repetitions of short sprints, with variable short recovery periods in-between. The specific test protocol can be easily adapted to suit the specific needs and activity patterns of intermittent-type sports. RSTs are most commonly used in multi-sprint team sports such as soccer, rugby, and hockey. Surprisingly, the RST have never been performed among young tennis players.

The aim of the present study, therefore, was to determine the performance indices and the physiological responses of two RST ( $10 \mathrm{~m}$ and $20 \mathrm{~m}$ repetitions) protocols and to examine their relationships with the aerobic fitness in young tennis players. 


\section{MATERIALS AND METHODS}

\section{Participants}

Fifteen young trained male tennis players (age $14.8 \pm 1.0$ yrs, body mass $64.9 \pm 7.4 \mathrm{~kg}$, height $159.9 \pm 7.6 \mathrm{~cm}$ ) participated in the study. The players had average of 5-6 yrs playing experience. The players had four tennis training sessions a week, each of $2 \mathrm{hrs}$. They also had three tennis-specific conditioning sessions a week, $45 \mathrm{~min}$ each, including agility, speed and specific coordination drills. Participants competed in occasional tournaments, every few weeks throughout the year, with a total of 20 to 25 matches per year. A standard calibrated scale and stadiometer were used to determine height and body mass. The study was approved by the Institution's ethical committee, the testing procedure was explained, and a written informed consent was obtained from all players and their parents.

\section{Testing procedures}

The participants performed three tests in random order, separated by 4 to 5 days from each other and at least 48 hours prior or after to a match. The three tests included an aerobic power test, and two RSTs. In order to prevent unnecessary fatigue effect, players and coaches were instructed to avoid intense training 24-hours prior to each testing session. The aerobic power test and the two RSTs were performed in the team home sports arena. All tests were performed in the afternoon, three hours after lunch and in a comfortable average air temperature of about $24^{\circ} \mathrm{C}$.

\section{Repeated sprint test}

Prior to the RSTs participants performed a 20-25 min specific warm-up. Each RST protocol included a series of short maximal running with short rest periods between runs. The two protocols consisted of the following parameters;

1. Twelve times all-out $10 \mathrm{~m}$ sprint departing every $20 \mathrm{~s}$

2. Twelve times all-out $20 \mathrm{~m}$ sprint departing every $20 \mathrm{~s}$

A $10 \mathrm{~m}$ and a $20 \mathrm{~m}$ all-out sprints were performed following the warm-up of the $12 \times 10 \mathrm{~m}$ and the $12 \times 20 \mathrm{~m}$ protocols, respectively, by each subject. The time for each sprint was used as the criterion score during the subsequent RST. In the first sprint of each RST, subjects were required to achieve at least $95 \%$ of their criterion score. If $95 \%$ of the criterion score was not achieved, the subject 
was required to re-start the RST. A photoelectric cell timing system (AlgeTiming Electronic, Vienna, Austria) linked to a digital chronoscope was used to record each sprint and rest interval time with an accuracy of $0.001 \mathrm{~s}$. During the recovery between sprints, subjects tapered down and slowly walked back to the next start point. Two sets of timing gates were used, working in opposite directions, to allow subjects to start the next run from the same end that they finished the preceding sprint, thus eliminating the need to hurry back to a common starting point. A standing start, with the front foot placed $30 \mathrm{~cm}$ behind the timing lights, was used for all sprints. Timing was initiated when the subject broke the light beam. An experimenter was placed at each end of the track to give strong verbal encouragement to each subject at each sprint. Subjects were instructed prior to the test to produce maximal effort for each sprint and to avoid pacing themselves.

The three measures for each RST $(12 \times 10 \mathrm{~m}$ and $12 \times 20 \mathrm{~m})$ were the ideal $10 \mathrm{~m}$ or $20 \mathrm{~m}$ sprint time (IS), the total accumulated sprinting time (TS) of the 12 sprints of each RST, and the performance decrement (PD) during each test. IS was calculated as the fastest $10 \mathrm{~m}$ or $20 \mathrm{~m}$ sprint time multiplied by 12 . TS was calculated as the sum of all sprint times. PD was used as an indication of fatigue and was calculated as [(TS/IS)X100]-100 [4]. The test-retest reliability of running RST is 0.942 for TS, and 0.75 for PD [4].

Heart rate was measured using a Polar heart rate monitor (Polar Accurex Plus, Polar Electro, Woodbury, NY) immediately upon completion of each repeated test.

\section{Aerobic power test - twenty-meter shuttle run test}

The $20 \mathrm{~m}$ shuttle run test is a field test that predicts aerobic fitness $\left(\mathrm{VO}_{2} \mathrm{max}\right)$ and has been shown to be a reliable and valid indicator of aerobic power in various populations [16]. The test consisted of shuttle running at increasing speeds between two markers placed $20 \mathrm{~m}$ apart. A portable compact disc (Sony CFD-V7) dictated the test pace by emitting tones at appropriate intervals. Subjects were required to be at one end of the $20 \mathrm{~m}$ course at the signal. A start speed of $8.5 \mathrm{~km} /$ hour was maintained for one minute, and was increased by $0.5 \mathrm{~km} /$ hour every minute thereafter. The test score achieved was the number of $20 \mathrm{~m}$ laps completed before the subject either withdrew voluntarily from the test or failed to arrive within $3 \mathrm{~m}$ of the end line on two consecutive tones. $\mathrm{VO}_{2}$ max was derived by the formula: $\mathrm{Y}=6.0 \mathrm{X}-24.4$, where $\mathrm{y}=$ predicted $\mathrm{VO}_{2} \max$ and $\mathrm{X}=$ maximum speed achieved [18]. 


\section{Statistical Analysis}

Paired t-test was used to compare differences between the performance indices (IS, TS, PD) and heart rate following the two RSTs. Pearson correlations were computed between performance indices of the two RSTs $(12 \times 10 \mathrm{~m}$ and $12 \times 20 \mathrm{~m}$ ) and between each RST and the calculated $\mathrm{VO}_{2}$ max. Data are presented as mean \pm SD. Significance level was set at $\mathrm{p}<0.05$.

\section{RESULTS}

Performance indices of both sprints protocols (short $-12 \times 10 \mathrm{~m}$ and long $12 \times 20 \mathrm{~m}$ ) are presented in Table 1 . IS and TS were significantly higher in the long compared to the short RST protocol ( 41.98 vs $23.36 \mathrm{~s}$ and $43.24 \mathrm{vs} 24.18$ $\mathrm{s}$, respectively). PD in the long protocol was higher, although not significantly, compared to the short protocol (3.6 and 3.0\%, respectively). Peak heart rate was significantly higher at the end of the long protocol $(181.7 \mathrm{~b} / \mathrm{min})$ compared the short protocol $(168.2 \mathrm{~b} / \mathrm{min})$.

Table 1. Performance indices (Mean \pm SD) of the two RST protocols

\begin{tabular}{lcccc}
\hline Protocol & $\begin{array}{c}\text { Ideal Sprint } \\
\text { Time (s) }\end{array}$ & $\begin{array}{c}\text { Total Sprint } \\
\text { Time (s) }\end{array}$ & $\begin{array}{c}\text { Performance } \\
\text { Decrement (\%) }\end{array}$ & $\begin{array}{c}\text { Peak Heart Rate } \\
\text { (b/min) }\end{array}$ \\
\hline $12 \times 10 \mathrm{~m}$ & $23.36 \pm 1.74^{*}$ & $24.18 \pm 1.74^{\star}$ & $3.6 \pm 2.3$ & $181.7 \pm 13.1^{*}$ \\
\hline $12 \times 20 \mathrm{~m}$ & $41.98 \pm 3.18$ & $43.24 \pm 3.26$ & $3.0 \pm 1.0$ & $168.2 \pm 11.3$ \\
\hline
\end{tabular}

Note: ${ }^{*} \mathrm{p}<0.05$ for between-test differences

The correlations between performance indices of the two RST protocols are presented in Table 2. Significant correlations were found between the IS $(\mathrm{r}=0.946)$ and between the TS $(\mathrm{r}=0.932)$, but not between the PD $(\mathrm{r}=-0.180)$, of the two RST protocols. Significant correlations were also found between the $12 \times 20 \mathrm{~m}$ TS and the $12 \times 10 \mathrm{~m}$ IS $(\mathrm{r}=0.938)$ and between the $12 \times 20 \mathrm{~m}$ IS and the $12 \times 10 \mathrm{~m}$ TS $(\mathrm{r}=0.948)$ of the two RST protocols. No significant correlations were found between the $12 \times 10 \mathrm{~m}$ PD and the $12 \times 20 \mathrm{~m}$ IS or TS. No significant correlations were also found between the $12 \times 20 \mathrm{~m}$ PD and the $12 \times 10 \mathrm{~m}$ IS or TS. 
Table 2. Relationships between performance indices in the two RST protocols

\begin{tabular}{llccc}
\hline $\begin{array}{l}\text { RST } \\
\text { Protocol }\end{array}$ & Indices & $\begin{array}{c}\text { I2x10 } \mathbf{~ m} \\
\text { Ideal Sprint } \\
\text { Time }\end{array}$ & $\begin{array}{c}\text { Total Sprint } \\
\text { Time }\end{array}$ & $\begin{array}{c}\text { Performance } \\
\text { Decrement }\end{array}$ \\
\hline \multirow{3}{*}{$12 \times 20 \mathrm{~m}$} & Ideal Sprint Time & $0.946^{*}$ & $0.948^{*}$ & -0.350 \\
\cline { 2 - 5 } & Total Sprint Time & $0.938^{*}$ & $0.932^{*}$ & -0.112 \\
\cline { 2 - 5 } & Performance Decrement & 0.081 & -0.142 & -0.180 \\
\hline
\end{tabular}

Note: *Significant correlation at $\mathrm{p}<0.05$

Table 3 presents the correlations between the calculated $\mathrm{VO}_{2}$ max and the performance indices of both RSTs. Significant correlations were found between the IS or the TS and $\mathrm{VO}_{2} \max$ in the short protocol ( $\mathrm{r}=-0.595$ and $\mathrm{r}=-0.594$, respectively). Significant correlations were also found between the IS or the TS and the $\mathrm{VO}_{2} \max$ in the long protocol $(\mathrm{r}=-0.716$ and $\mathrm{r}=-0.757$, respectively). No significant correlations were found between each of the two protocols PD and the VO max.

Table 3. Relationships between calculated $\mathrm{VO}_{2}$ max and performance indices in the two RSTs

\begin{tabular}{ccc}
\hline RST Protocol & Performance indices & $\mathrm{VO}_{2} \mathrm{max}$ \\
\hline \multirow{3}{*}{$12 \times 10 \mathrm{~m}$} & $\mathrm{IS}$ & $-0.595^{*}$ \\
\cline { 2 - 3 } & $\mathrm{TS}$ & $-0.594^{*}$ \\
\cline { 2 - 3 } $12 \times 20 \mathrm{~m}$ & $\mathrm{PD}$ & -0.083 \\
\cline { 2 - 3 } & IS & $-0.716^{*}$ \\
\cline { 2 - 3 } & TS & $-0.757^{*}$ \\
\hline \multirow{2}{*}{12} & -0.345 \\
\hline
\end{tabular}

*Significant correlation at $\mathrm{p}<0.05$

\section{DISCUSSION}

The findings of the present study display strong significant relationships between matched performance indices of the short and long RST protocols. In addition, a significant correlation was found between the athlete's aerobic fitness (calculated $\mathrm{VO}_{2} \max$ ) and the TS or the IS in both RSTs.

The physiological responses to intermittent exercise depend primarily on the subject's ability to recover from periods of work, and on the specific protocol used. Thus, performance depends on the duration of repetitions, duration of rest periods, and number of repetitions performed in a given work session. 
Different protocols for RST consist of 6-12 all-out sprints intercepted by rest intervals of 20 to $40 \mathrm{~s}$. The specific test protocol is adapted to suit the specific needs and activity patterns of the specific sport. The mean duration of work and rest periods in tennis are $1-10 \mathrm{~s}$ and $10-20 \mathrm{~s}$, respectively [3, 10, 17]. Therefore, short sprints and short periods of recovery seem to be appropriate for RST in tennis. The strong correlations between the performance indices of the two RSTs in the present study may confirm that both protocols represent similar physiological entities and that both are applicable for tennis. In a similar study, Meckel et al. [13] found only low to moderate correlations between matched performance indices of two RST protocols in a group of soccer players. However, in that study one RST protocol involved $12 \times 20 \mathrm{~m}$ while the other included $6 \times 40 \mathrm{~m}$. Thus, it seems that although they used the same repeated activity pattern and perform an equal total work, the RSTs were different from one another and may represent different physiological entities. These results emphasize the need for a selection of an appropriate RST proto$\mathrm{col}$ - one that will match the work-rest pattern and physiological demands of the relevant sport. Although the present findings demonstrate physiological resemblance between the two RSTs, one should consider the influence of the court surface and its application on game activity patter. Therefore, given that clay court tennis matches are relatively slow and long lasting and grass court matches are usually fast and short [11], the long $12 \times 20 \mathrm{~m}$ RST may better suit clay specialist players while the short $12 \times 10 \mathrm{~m}$ RST may better suit grass specialist players [16].

The relevance of the aerobic energy system to power maintenance during intermittent activity was evaluated in the present study by a correlation coefficient analysis between the performance indices in each RST and the calculated $\mathrm{VO}_{2}$ max of the participants. Significant correlations were found between the IS or the TS and $\mathrm{VO}_{2}$ max in the short protocol $(\mathrm{r}=-0.595$ and $\mathrm{r}=-0.594$, respectively). Significant correlations were also found between the IS or the TS and the $\mathrm{VO}_{2}$ max in the long protocol ( $\mathrm{r}=-0.716$ and $\mathrm{r}=-0.757$, respectively). The assumption that the aerobic energy system is an important determinant in recovery rate from intense activity and therefore assists in power output maintenance during the RST, relies on the fact that creatine phosphate re-synthesis occurs primarily by oxidative processes $[7,19]$. However, results of previous studies were inconsistent and reported non-significant to moderate correlations $(0.42<\mathrm{r}<0.62)$ between $\mathrm{VO}_{2}$ max and performance indices in intermittent type of activity $[1,7,13,19]$. One possible reason for these differences may come from the fact that these studies used different protocols with large variations in the number and length of repetitions and time of rest periods. Obviously, 
although using a repeated activity pattern, the differences between protocols may change the energy demands and the physiological responses during the RSTs. Only when the RST protocol is specific to the sport involved and truly represent its movement pattern, a valid conclusion can be made concerning the relationship between $\mathrm{VO}_{2} \max$ and RST performance indices and the importance of aerobic fitness to power maintenance in that sport. However, if the movement pattern of a given sport is complex (as in tennis) and an appropriate protocol is difficult to identify, two protocols should be tested, as was done in the present study. The findings of our study suggest that the aerobic system is involved in the energy regulation of both RST protocols. However, it seems that the greater the total work, the greater the involvement of the aerobic energy system. In line with that, Gatanos et al. [5] suggested that the aerobic energy system contribution to the total energy provision increased significantly, and was more important (as compared to glycolysis) in power output maintenance during a long series of repeated sprints. They speculated that during the last sprinting efforts, glycolysis was exhausted and the contribution of the aerobic system to ATP re-synthesis was more significant. The longer total sprint and running time of the long protocol $(12 \times 20 \mathrm{~m})$ in the present study, and our finding of stronger correlation between TS in the long RST and the calculated $\mathrm{VO}_{2} \mathrm{max}$, seems to be consistent with this theory. Again, one should also consider the fact that tennis matches on hard surface courts (e.g., grass) are usually short and intense compared to the relatively slow and long games performed on soft surface courts (e.g., clay). Given that, it seems that the involvement of the aerobic fitness to tennis is more important in clay surface matches.

In conclusion, short repetition RST $(12 \times 10 \mathrm{~m})$ protocol and long repetition RST protocol $(12 \times 20 \mathrm{~m})$ seem to represent similar physiological entities and performance capabilities. Therefore, both protocols seem to be appropriate for tennis. In addition, the aerobic energy system serves as a significant factor in both short and long RTS protocols. However, the higher total work performed in the long repetition RST leads to a greater involvement of the aerobic system in the long, compared to the short, RST protocol. The results also highlight the possible greater importance of aerobic fitness for soft surface tennis players compared to hard surface specialist. Consequently, soft surface specialist should include more aerobic-type training in their conditioning program than hard surface specialist. 


\section{REFERENCES}

1. Bishop D, Spencer M, Duffield R, Lawrence S. (2001) The validity of a repeated sprint ability test. J Sci Med Sport, 4: 19-29

2. Christmass AM, Richmond ES, Cables TN, Arthur GP, Hartmann EP. (1997) Exercise intensity and metabolic response in singles tennis. J Sports Sci, 16: 739-747

3. Fernandez J, Mendez-Villanueva A, Pluim BM. (2006) Intensity of tennis match play. Br J Sports Med, 40: 387-391

4. Fitzsimons M, Dawson BT, Ward D, Wilkinson A. (1993) Cycling and running tests of repeated sprint ability. Aus J Sci Med Sport, 25: 82-87

5. Gaitanos GC, Williams C, Boobis LH, Brooks S. (1993) Human muscle metabolism during intermittent maximal exercise. J Appl Physiol, 75: 712-719

6. Girard O, Millet GP. (2009) Physical determination of tennis performance in competitive teenage players. J Strength Cond Res, 23: 1867-1872

7. Glaister M. (2005) Multiple-sprint work: physiological responses, mechanisms of fatigue and the influence of aerobic fitness. Sports Med, 35: 757-777

8. Kibler WB, Mcqueen C, Uhl T. (1988) Fitness evaluation and fitness findings in competitive tennis players. Clin Sports Med, 7: 403-416

9. König D, Huonker M, Schmid A, Halle M, Berg A, Keul J. (2001) Cardiovascular, metabolic, and hormonal parameters in professional tennis players. Med Sci Sports Exerc, 33: 654-658

10. Kovacs MS. (2006) Applied physiology of tennis performance. Br J Sports Med, 40: $381-386$

11. Kovacs MS. (2007) Tennis physiology: training the competitive athlete. Sports Med, 37: 189-198

12. Lees A. (2003) Science and the major racket sports: a review. J Sports Sci, 21: 707-732

13. Meckel Y, Machnai O, Eliakim A. (2009) Relationship among repeated sprint tests, aerobic fitness and anaerobic fitness in elite adolescent soccer players. J Strength Cond Res, 23: 163-169

14. Perry AC, Wang X, Feldman BB et al. (2004) Can laboratory-based tennis profiles predict field tests of tennis performance? J Strength Cond Res, 18: 136-143

15. Roetert EP, Garret GE, Brown SW, Camaione DN. (1992) Performance profiles of nationally ranked junior tennis players. J Appl Sport Sci Res, 6: 225-231

16. Smekal G, Pokan R, Von Duvillard SP, Baron R, Tschan H, Bachl N. (2000) Comparison of laboratory and "on-court" endurance testing in tennis. Int J Sports Med, 21: 242-249

17. Smekal G, Von Duvillard SP, Rihacek C. (2001) A physiological profile of tennis match play. J Med Sci Sports Exerc, 33: 999-1005 
18. St Clair Gibson A, Broomhead S, Lambert MI, Hawley JA. (1998) Prediction of maximal oxygen uptake from a $20 \mathrm{~m}$ shuttle run as measured directly in runners and squash players. J Sports Sci, 16: 331-335

19. Tomlin DL, Wenger HA. (2001) The relationship between aerobic fitness and recovery from high intensity intermittent exercise. Sports Med, 31: 1-11

\section{Correspondence to:}

Igal Tsiprun,

Wingate Institute of Physical Education and Sport

Netanya 42902

Israel 